International Journal of Poultry Science 8 (6): 565-569, 2009

ISSN 1682-8356

(C) Asian Network for Scientific Information, 2009

\title{
Probability Mapping for Mycoplasma gallisepticum Risk in Backyard Chickens in Paraguay
}

\author{
M. Herrero', K. Suzuki', J. Origlia', L. Nuñez², M. Faccioli², M. Silva², \\ J. Caballero ${ }^{2}, \mathrm{O}$. Valiente ${ }^{2}$ and F. Álvarez ${ }^{2}$ \\ 'Laboratorio de Diagnóstico de Enfermedades de las Aves y los Pilíferos, \\ Facultad de Ciencias Veterinarias, Universidad Nacional de La Plata, Argentina \\ ${ }^{2}$ Laboratorio de Diagnóstico de las Enfermedades de las Aves, Facultad de Ciencias Veterinarias, \\ Universidad Nacional de Asunción, Paraguay
}

\begin{abstract}
Poultry production is a growing industry in Paraguay, South America. The insufficient farm management methods commonly used in backyard chickens make them a potential reservoir for economically important diseases such as Mycoplasma gallisepticum that can influence commercial poultry operations. There are no previous studies on a survey of Mycoplasma gallisepticum among backyard chicken population in Paraguay. The objectives of this study were: (a) to determine the seroprevalence of Mycoplasma gallisepticum in backyard chickens in Paraguay and (b) to generate choropleth maps for the Standardized Risk Ratio (SRR) for Mycoplasma gallisepticum in the study chickens and Poison probabilities for the SRR, in place of using the raw seroprevalence. Paraguay is divided into 17 departments. A department-stratified random sampling was planned and conducted. The required total sample size of 1291 from a chicken population of 17 million was sufficient to produce a $95 \%$ confidence interval with a desired precision of $\pm 2.5 \%$ when the estimated antibody seroprevalence was $30 \%$. Sera were analyzed using a commercial indirect ELISA. The observed overall seroprevalence was $26 \%$. The resulting maps for the SRR for Mycoplasma gallisepticum in the study chickens at department level and Poison probabilities for the SRR were depicted. Departments with significantly high or low disease risks were confirmed. Different types of epidemiological parameters can be calculated to take account of potential risk factors. Therefore, further detailed investigations into those risk factors associated with Mycoplasma gallisepticum occurrence with respect to spatially epidemiological differences would be of interest.
\end{abstract}

Key words: Choropleth map, data visualization, smallholders, South America

\section{INTRODUCTION}

Mycoplasma gallisepticum (MG) is a considerable and economically important pathogen of avian species. The MG is the etiological agent of chronic respiratory disease in chickens and may be horizontally and vertically infected. Chickens infected with MG become lessening in egg productivity, hatchability and feed efficiency and grows in mortality, waste carcass and veterinary costs (Kleven, 2005; Ley, 2003). Increasingly, these possible performance and production deprivations require the strict control of MG amongst all the poultry sectors.

Poultry production is a growing industry in Paraguay. Several commercial poultry operations have been developed in the vicinity of some urban areas. The insufficient farm management methods commonly used in backyard chickens make them a potential reservoir for diseases such as MG that can influence commercial poultry operations. Investigations into the diseases including $M G$ of backyard chickens in the world are rare (Hernandez-Divers et al., 2006; Kelley et al., 1994; McBride et al., 1991), but should be encouraged. There are no previous studies, as far as the authors know, on a MG survey among backyard chicken population in Paraguay.

Incidentally, the most commonly applied spatially epidemiological analysis technique in surveys of animal diseases is data visualization. This includes producing maps to show the spatial patterns of disease occurrence, which are then used to develop hypotheses about potential cause-effect associations. While a choropleth map showing the proportion classified as test positive of a disease (e.g. raw seroprevalence) is easy to understand, it has disadvantage that the size of the areas and the location of their borders is typically an indication of administrative requirements rather than of the geographical distribution of epidemiological elements. The objectives of this study were: (a) to determine the seroprevalence of $M G$ in backyard chickens in Paraguay and (b) to generate maps for the Standardized Risk Ratio (SRR) for MG in the study chickens and Poison probabilities for the SRR, in place of using the raw seroprevalence.

Corresponding author: K. Suzuki, PROVETSUR, Facultad de Ciencias Veterinarias, Universidad Nacional de La Plata, CC296, La Plata, B1900AVW, Argentina. Tel/Fax: +542214253276 
Int. J. Poult. Sci., 8 (6): 565-569, 2009

\section{MATERIALS AND METHODS}

Study area: Paraguay is a fully landlocked country with a land area of $406,752 \mathrm{~km}^{2}$, located in the centre of South America, bordering Argentina to the south and southwest, Brazil to the east and northeast and Bolivia to the northwest. Paraguay consists of 17 departments and one capital district. The population is currently estimated at 6.2 million people, of which 3.6 million live in the capital city Asunción, its surroundings and other urban areas. About $40 \%$ of the total population engages in agricultural sector. The climate in Paraguay is subtropical with mean monthly temperature varying from $18^{\circ} \mathrm{C}$ in winter and $28^{\circ} \mathrm{C}$ in summer. Mean annual rainfall ranges between $750 \mathrm{~mm}$ and $1250 \mathrm{~mm}$, increasing southwards. Paraguay has a poultry population of 17 million, a poultry meat production of 37,000 tonnes per year and a poultry egg production of 100,000 tonnes per year (FAO, 2001, 2005, 2009).

Data and sample collections: The Paraguay government's Statistical Yearbook 2006 used for this study included data on the number of chickens at department level (DGEEC, 2008). A map of administrative boundaries was obtained from the GIS Download Data Server (CIP, 2005). A choropleth map based on the percentage to the total chicken population of Paraguay at department level was produced using the geographical information system software ArcGlS version 9.2 (ESRI Inc., Redlands, CA, USA). All the departments were classified into four groups, on the basis of the percentage to the total chicken population using built-in Natural Breaks (Jenks) function in the software: $<2 \%, 2-6 \%, 6-9 \%$ and $9-16 \%$.

The Paraguay government's National Animal Quality and Health Service [Servicio Nacional de Calidad y Salud Animal (SENACSA)] planned a department-stratified random sampling, originally for a nationwide survey for Newcastle Disease and Avian Influenza in backyard chickens in Paraguay (SENACSA, 2006). The required total sample size of 1291 from a chicken population of 17 million was sufficient to produce a $95 \%$ Confidence Interval $(\mathrm{Cl})$ with a desired precision of $\pm 2.5 \%$ when the estimated antibody seroprevalence was $30 \%$. The sample size in each of the departments was allocated by the available financial, human and material means. The field work was conducted in 2006 , consisted of data collection through questionnaire interviews for each smallholder farming household, together with blood sample collections for each backyard chicken.

Laboratory examinations and data analysis: Sera imparted by SENACSA were analyzed using a commercial indirect ELISA (FlockChek ${ }^{\text {(a) }}$ MG, IDEXX Laboratories Inc., Westbrook, ME, USA) as indicated by the manufacturer instruction for detecting antibodies against MG, between March and July 2008. Absorbance was read on an ELISA reader at $650 \mathrm{~nm}$. A level of antibody titres greater than 1076 was considered positive. Given the limited use of vaccine against any diseases in the backyard chicken population in Paraguay, most of the results of laboratory examinations would be ascribed to natural exposure to MG (SENACSA, 2006, personal communication). After obtaining the results of laboratory examinations, power analysis for the overall proportion classified as test positive (raw seroprevalence) was conducted using the statistical power analysis software PASS 2008 version 08.0.8 (Number Cruncher Statistical Systems, Kaysville, UT, USA). Cls of raw seroprevalence in each of the departments were calculated using Wilson's method (Newcombe, 1998). The ELISA sensitivity and specificity values were not publicized and therefore further calculations for true prevalence estimation (Rogan and Gladen, 1978) were not implemented.

The estimated number of positives in each of the apartments $y_{i}$ was obtained by multiplying the published chicken population in a department $n_{i}$ by the corresponding raw seroprevalence. The overall raw seroprevalence was assumed in fact constant for all departments and those departments were independent. Then a sensible supposition was that estimated number of positives $y_{i}$ were observations on independent Poison random variables with expected values $\mu_{i}$. In this case a reasonable estimate of the mean expected number in each department, $\mu_{i}$, was given by:

$$
\hat{\mu}_{i}=n_{i}\left(\frac{\sum y_{i}}{\sum n_{i}}\right)
$$

The Standardized Risk Ratio (SRR) in each of the departments was calculated by dividing the estimated number of positives $y_{i}$ by its estimated expected value, $\hat{\mu}_{i}$ (Dohoo et al., 2003). Thus a SRR value of 2 , for example, suggests that the estimated number of positives, $y_{i}$, in department $l$, is double what we expect, $\hat{\mu}_{i}$. All departments were categorized into four groups on the basis of the SRR values: 0.0-0.5, 0.6-1.0,1.1-1.5 and 1.6-2.3. A value $>1$ shows an association with high risk and value $<1$ with low risk. In addition to mapping the SRRs, a probability map was produced under the assumption that the estimated number of positives in each area / was Poison with mean value $\mu_{i}$. The $\mu_{i}$ was estimated in the same way as described above, obtaining $\hat{\mu}_{i}$. Then we map:

$$
p_{i}= \begin{cases}\sum_{x \geq y_{i}} \frac{\hat{\mu}_{i}^{x} e^{-\hat{\mu}_{i}}}{x !} & y_{i} \geq \hat{\mu}_{i} \\ \sum_{x<y_{i}} \frac{\hat{\mu}_{i}^{x} e^{-\hat{\mu}_{i}}}{x !} & y_{i}<\hat{\mu}_{i}\end{cases}
$$

Small or large values of $p_{i}$ (less than 0.05 , or more than 0.95 ) would then indicate that a department's SRR was unusually high or low (Norcliffe, 1980). The resulting 
maps for the SRRs and Poison probabilities were drawn using the MAPTOOLS package version $0.7-20$, in the $R$ software version 2.8.1 (Anon, 2009; R Development Core Team, 2008).

\section{RESULTS}

Figure 1 depicts a map showing the percentage to the total chicken population, in 17 departments of Paraguay. The capital city Asunción, where is a distinct administrative area from any other departments, is actually located in Central Department. The Central Department had the largest proportion of $16 \%$ to the total chicken population. The east side of the country had the concentration of chicken population, especially in the capital's surroundings and the vicinity of the other urban areas such as Ciudad del Este in Alto Paraná Department and Encarnación in Itapúa Department. While the three departments in the west side of the country (Presidente Hayes, Boquerón and Alto Paraguay) where were sparsely populated areas ( $<2$ people per $\mathrm{km}^{2}$ ) had less chicken population. The Alto Paraguay Department had the smallest proportion of $0.03 \%$ to the total chicken population. Table 1 shows descriptive results. The statistical precision was improved from $\pm 2.5 \%$ to $\pm 2.1 \%$ because of the eventual total number of samples of 1748 (larger than planned) and the overall raw seroprevalence of $26 \%$ (smaller than expected). Raw seroprevalence was highly variable between the study departments $(0-58 \%)$ on the basis of different sample sizes (33-292). The median number and range of the study households per department and chickens per household were 19 (range: 5-40) and 9 (range: 1-29), respectively. The resulting maps for the SRR for $M G$ in the study chickens and Poison probabilities for the SRR are shown in Fig. 2. Boquerón Department had the highest MG risk of 2.3 , followed by Alto Paraguay and Concepción Departments with the respective MG risks of 1.6. These three departments are on the border with neighbouring countries such as Argentina, Bolivia and Brazil. While Guairá Department had the lowest MG risk of 0.0 , followed by Cordillera and Paraguari Departments with the MG risks of 0.3 and 0.5 , respectively. These three departments are landlocked. The SRRs in each department were examined using the Poison probability map with more sensible assessments on a probability scale. There was no department with a probability of statistical insignificance. Small $(p<0.05)$ or large $(p>0.95)$ probabilities indicate that the study departments have significantly lower (SRR $<1.0$, number of departments applicable $=5$ ) or higher risk (SRR > 1.0, number of departments applicable = 10), respectively, with two exceptional departments of Alto Paraná and Ñeembucú having the risks of just 1.0.

\section{DISCUSSION}

This study demonstrated the utility of serum samples of backyard chickens officially collected, for analysis of

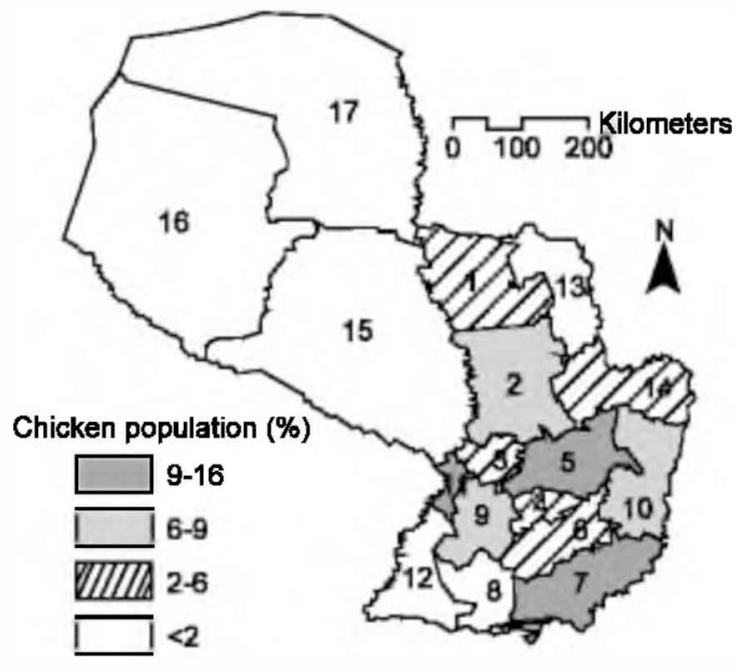

Fig. 1: A choropleth map based on the percentage to the total chicken population in 17 administrative departments of Paraguay. The departmental IDs (1-17) refer to values shown in Table 1
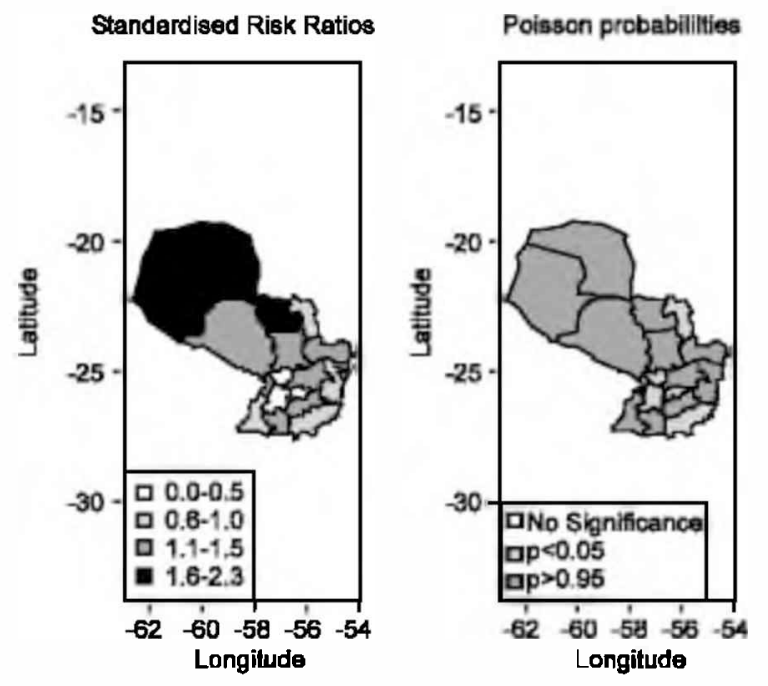

Fig. 2: Choropleth maps showing the Standardized Risk Ratios (SRRs) for Mycoplasma gallisepticum in backyard chickens in Paraguay (left) and Poison probabilities for the SRRs (right)

spatial characteristics of MG risk in Paraguay. The dataset provided information on the results of the diagnostic test for MG, allowing analysis of individualbased data for the study. The modest-sized dataset posed a few computational challenges and as a result, some analytical compromises had to be implemented. For example, the application of sampling weight correction techniques to the stratified survey dataset using the SURVEY package version $3.11-2$ in the $R$ 
Int. J. Poult. Sci., 8 (6): 565-569, 2009

Table 1: Raw seroprevalence for Mycoplasma gallisepticum in backyard chickens in Paraguay

\begin{tabular}{|c|c|c|c|c|c|}
\hline \multirow[b]{2}{*}{ ID } & \multirow[b]{2}{*}{ Department } & \multirow[b]{2}{*}{ No. of samples } & \multirow[b]{2}{*}{ Raw seroprevalence (\%) } & \multicolumn{2}{|l|}{$95 \% \mathrm{Cl}$} \\
\hline & & & & Lower & Upper \\
\hline 1 & Concepción & 61 & 41 & 30 & 54 \\
\hline 2 & San Pedro & 104 & 34 & 25 & 43 \\
\hline 3 & Cordillera & 139 & 7 & 4 & 13 \\
\hline 4 & Guairá & 127 & 0 & 0 & 3 \\
\hline 5 & Caaguazú & 166 & 39 & 32 & 47 \\
\hline 6 & Caazapá & 86 & 33 & 24 & 43 \\
\hline 7 & Itapúa & 173 & 18 & 13 & 24 \\
\hline 8 & Misiones & 50 & 30 & 19 & 44 \\
\hline 9 & Paraguarí & 99 & 13 & 8 & 21 \\
\hline 10 & Alto Paraná & 149 & 26 & 20 & 34 \\
\hline 11 & Central & 292 & 30 & 25 & 35 \\
\hline 12 & Ñeembucú & 76 & 26 & 18 & 37 \\
\hline 13 & Amambay & 48 & 19 & 10 & 32 \\
\hline 14 & Canindeyú & 36 & 33 & 20 & 50 \\
\hline 15 & Presidente Hayes & 50 & 34 & 22 & 48 \\
\hline 16 & Boquerón & 33 & 58 & 41 & 73 \\
\hline 17 & Alto Paraguay & 59 & 41 & 29 & 53 \\
\hline Total & & 1748 & 26 & 24 & 28 \\
\hline
\end{tabular}

software (Lumley, 2004, 2009), would have been desirable, but was not computationally possible. Seroprevalence at flock level was also not considered. In spite of the limitations, it is considered that the analysis has provided an accurate description of the spatial features of MG risk in Paraguay.

In this study, backyard chickens in Paraguay showed evidence of exposure to $M G$, one of important poultry pathogens. Paraná and Ñeembucú Departments had the same raw seroprevalence value of $26 \%$ as the value of the whole study area. The observed overall raw seroprevalence broadly agreed with the prevalence in backyard chickens (Hernandez-Divers et al, 2006; Kelley et al., 1994; McBride et al., 1991) and fancy breeding chickens (Wunderwald and Hoop, 2002) where flock management is comparable with backyard chickens.

In comparison with commercial poultry, backyard chickens are both at an advantage and disadvantage for retaining health. Backyard chickens are not given immunizations usually given to commercial poultry, involving vaccinating hens to raise maternal antibody passed to chicks. This makes backyard chickens intrinsically more sensitive to many infectious diseases. In addition, backyard chickens do not receive treatments frequently used in commercial poultry, such as coccidiostat drugs (SENACSA, 2006, personal communication). Commercial poultry are kept in single age groups in an "all in, all out" manner, while backyard chickens are in flocks of mixed ages, with susceptible chicks in touch with adults that are potential reservoirs for diseases. An infectious disease, therefore, could easily be maintained in a backyard chicken population by a constant supply of new susceptible hosts coming into contact with reservoir animals. The relatively high seroprevalence in some departments can be partly explained by repeated stimulation from close contact with bacteria due to the common rearing of various age groups. Most commercial poultry flocks are kept free of certain infectious diseases including $M G$, which can be transmitted from the hen to her progeny (SENACSA, 2006, personal communication). Because backyard chickens are not kept under observation for the diseases, diseases would remain endemic in the population through continued egg transmission.

When the attribute of interest is a proportion (e.g. raw seroprevalence), exploratory mapping of the proportions to present spatial variability is a clear first measure in any analysis. However, using the raw observed proportions may be misleading, because the variability of such proportions will be a dependence on the values of the population to which they relate and this may differ widely between areas (Bailey and Gatrell, 1995). An alternative method for evaluating these data would be to focus on the differences between the departments and national average in the case of this study. The SRR is used in representing spatial characteristics of disease distribution. It standardizes the data by re-expressing them as the ratio between the estimated number of positives and the number that would have been expected in a standard population. Figure 2 (left) presents SRR estimates for MG-positive backyard chickens aggregated at department level. This is mostly a dependence on sample size and it is therefore suitable to accompany the map with a presentation of the probability of the estimates, such as Fig. 2 (right).

As the objective of these map presentations is to identify departments with unusually high or low disease risks, different types of epidemiological parameters can be calculated to take account of potential risk factors, such as the spatial heterogeneity of the underlying population at risk. Therefore, further detailed investigations into those risk factors associated with MG occurrence with 
Int. J. Poult. Sci., 8 (6): 565-569, 2009

respect to spatially epidemiological differences would be of interest.

\section{ACKNOWLEDGEMEMT}

This study was carried out as part of the project for the capacity development for improvement of livestock hygiene in the southern part of South America through regional cooperation [commonly known as: Proyecto de desarrollo profesional continuo para los veterinarios del Sur (PROVETSUR)], funded by the Japan International Cooperation Agency.

\section{REFERENCES}

Anon, 2009. MAPTOOLS: tools for reading and handling spatial objects. $R$ package version 0.7-20. Available from: http://cran.r-project.org/web/packages/ maptools/index.html.

Bailey, T.C. and A.C. Gatrell, 1995. Interactive spatial data analysis. Longman, Harlow, pp: 413.

CIP, 2005. GIS download data server. Centro Internacional de la Papa (CIP), Lima. Available from: http://research.cip.cgiar.org/gis/index.php.

DGEEC, 2008. Anuario estadístico del Paraguay 2006 (in Spanish). Dirección General de Estadistica, Encuestas y Censos (DGEEC), Asunción. Available from: http://uww.dgeec.gov.py/Publicaciones/ Biblioteca/Anuario2006/Anuario2006.htm

Dohoo, I., W. Martin and H. Stryhn, 2003. Veterinary epidemiologic research. AVC, Charlottetown, pp: 706.

FAO, 2001. FAOCLIM 2: world-wide agroclimatic data (CD-ROM database). Rome.

FAO, 2005. New_LocClim: local climate estimator. Rome. Available from: ftp://ext-ftp.fao.org/SD/ Reserved/Agromet/New_LocClim/.

FAO, 2009. FAOSTAT. Rome. Available from: http://faostat.fao.org/.

Hernandez-Divers, S.M., P. Villegas, F. Prieto, J.C. Unda, N. Stedman, B. Ritchie, R. Carroll and S.J. Hernandez-Divers, 2006. A survey of selected avian pathogens of backyard poultry in northwestern Ecuador. J. Avian Med. Surg., 20: 147-158.
Kelley, P.J., D. Chitauro, C. Rohde, J. Rukwava, A. Majok, F. Davelaar and P.R. Mason, 1994. Diseases and management of backyard chicken flocks in Chitungwiza, Zimbabwe. Avian Dis., 38: 626-629.

Kleven, S.H., 2005. Poultry: mycoplasmosis, In: Kahn, C.M. (Ed.), The Merck veterinary manual, 9th edition, Merck and Co., Whitehouse Station, pp: 2242-2246.

Ley, D.H., 2003. Mycoplasma gallisepticum Infection, In: Saif, Y.M., H.J. Barnes, J.R. Glisson, A.M. Fadly, L.R. McDougald and D.E. Swayne (Eds.) Diseases of poultry, 11th Edn, lowa State University Press, Ames, pp: $722-743$.

Lumley, T., 2004. Analysis of complex survey samples. J. Stat. Softw. 9: 1-19.

Lumley, T., 2009. SURVEY: analysis of complex survey samples. R package version 3.11-2. Available from: http://cran.r-project.org/web/packages/survey/index. html.

McBride, M.D., D.W. Hird, T.E. Carpenter, K.P. Snipes, C. Danayeelmi and W.W. Utterback, 1991. Health survey of backyard poultry and other avian species located within one mile of commercial California meat-turkey flocks. Avian Dis., 35: 403-407.

Newcombe, R.G., 1998, Two-sided confidence intervals for the single proportion: comparison of seven methods. Stat. Med., 17: 857-872.

Norcliffe, G.B., 1980. Inferential statistics for geographers. Hutchinson, London, pp: 272.

R Development Core Team, 2008. R: a language and environment for statistical computing. Available from: http://umw.R-project.org.

Rogan, W.J. and B. Gladen, 1978. Estimating prevalence from results of a screening-test. Am. J. Epidemiol., 107: 71-76.

SENACSA, 2006. Vigilancia epidemiológica de Newcastle e Influenza Aviar muestreo nacional según departamento año 2006 (in Spanish), In: Anuario 2006: estadistica pecuaria. Servicio Nacional de Calidad y Salud Animal (SENACSA), Asunción.

Wunderwald, C. and R.K. Hoop, 2002. Serological monitoring of 40 Swiss fancy breed poultry flocks. Avian Pathol., 31: 157-162. 